\title{
THE LUMINOUS PROPERTIES OF ELECTRICALLY CONDUCTING HELIUM GAS.
}

\author{
By P. G. Nutting.
}

\section{INTRODUCTION.}

A gas conducting an electric current radiates the energy imparted to it by the current. Neglecting relatively very slight losses due to conduction and convection, the efficiency of such a gas as a transformer of energy from electrical energy into radiation should be a constant approaching unity in value. Radiation from a gas should then be expressible in terms of current and other specificable conditions with considerable precision. To express this radiation in terms of light, the spectral distribution of the radiation and the visual sensibility of the observer must be known. Upon the constancy of these latter depends the constancy of the relation of light to current.

The results here presented relate to the amount of light per unit length emitted laterally by a column of helium gas carrying a known current. The chief object of the investigation was to determine the constancy and reproducibility of such a source of light and the specifications most favorable to constancy and reproducibility. The variation of light emitted with current, potential gradient, gas density, frequency of alternation of current, orientation of tube, with diameter of capillary and with time were studied in turn.

Conducting helium emits light of a yellowish white color better for photometric comparisons with a glow lamp than that from any other of the permanent gases. Next best is, perhaps, carbon dioxide. This emits a snow-white light, but decomposes and disappears rap22832-08-4 
idly, with but moderate current densities. Sulphur vapor emits bluisli-white light, but its density is difficult to measure and control. Helium has the further great advantage of not disappearing rapidly as other gases do when conducting a heavy current. The life of a tube of helinun is at least fifty hours as compared with half an hour for a similar tube of hydrogen or nitrogen carrying the same current.

Preliminary tests with tubes of various forms led to the adoption of a simple straight form with disk electrodes. The electrodes are of aluminum $\mathrm{I} .5 \mathrm{~mm}$ thick and $25 \mathrm{~mm}$ diameter in spherical bulbs

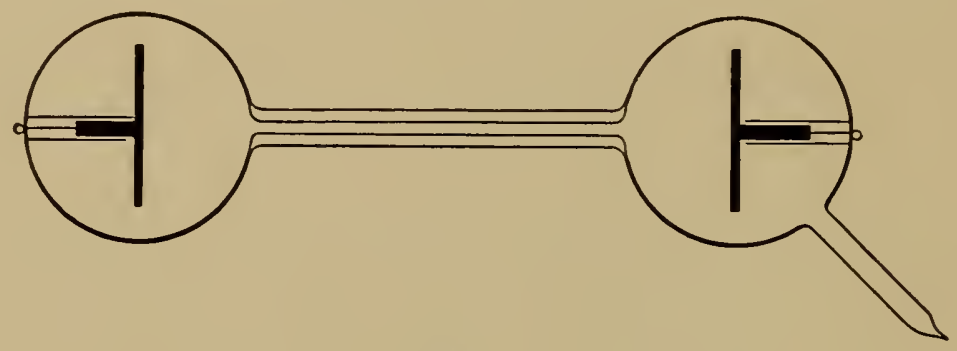

Fig. I.

$35 \mathrm{~mm}$ in diameter. These bulbs are connected by a straight piece of capillary tubing $50 \mathrm{~mm}$ in length and $2 \mathrm{~mm}$ in internal diameter. Foil $5 \mathrm{~mm}$ wide was wound about either end of the capillary to give the light emitting portion a definite measurable length. Light from the bulbs was screened off from the photometer.

\section{METHOD OF PREPARING TUBES.}

Ordinary methods were used in filling except that extra precautions were taken to free the electrodes from hydrogen. The tubes were cleaned with chromic acid and water and exhausted with a Geryk oil pump. After from twenty minutes to an hour of steady pumping with heavy current running through the tube, the last trace of hydrogen disappeared. Then helin1n was admitted, its pressure adjusted to about $5 \mathrm{~mm}$ and measured by means of au oil manometer of special design and the tube sealed off. The apparatus used in filling the tubes with pure helium at the proper pressure is shown in Fig. 2. Four very carefully ground stopcocks of 3 or 4 $\mathrm{mm}$ bore are joined in a line about $\mathrm{I} 0 \mathrm{~cm}$ apart. The onter end of the first is fitted with a ground joint for attaching to the pump. 
Between the first and second is attached a small auxiliary Plücker tube to aid in adjusting the pressure and testing the vacuum. Between the second and third cocks is attached an oil manometer of special design and a branch for attaching and sealing off the tubes to be filled. The space between the third and fourth cocks serves as an auxiliary reservoir in admitting helinm and protects the open helium bulb in case the apparatus remains idle for a considerable time. Beyond the fourth cock is a piece of large tubing to which the bulb of helium is cemented.

The sealed bulb containing helium must be opened without exposing the helium to contact with rubber tubing, water, or mercury. To accomplish this a massive piece of glass rod or capillary

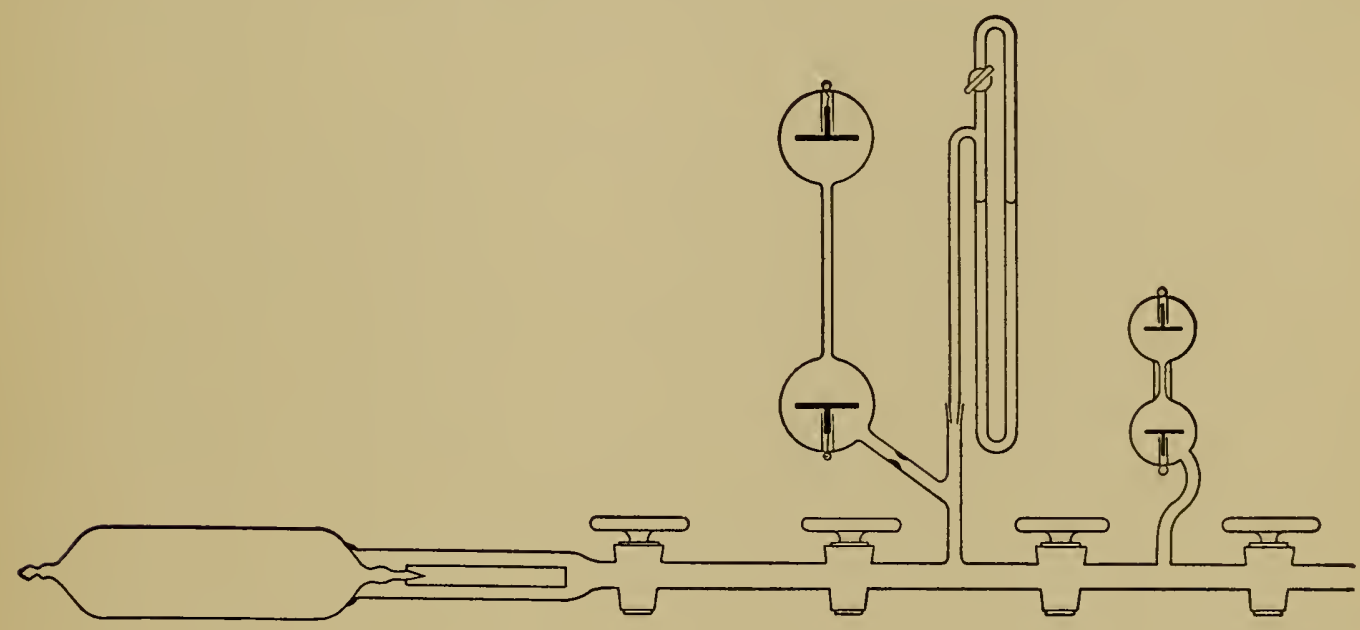

Fig. 2.

(metals contain too much absorbed gas) is cemented to the end of one tip and the neck of the tip scratched for breaking. The whole tip and weight is then inserted in the large tubing projecting beyond the fourth stopcock and the bulb back of the tip cemented, as shown, to this tubing with a fusible cement (rubber dissolved in resin and boiled in a vacuum). After the apparatus has been exhausted to a nonconducting vacuum for several days, a sharp tap will crack off the tip of the helium bulb and liberate the gas. A reservoir opened in this manner may be drawn from for months without contanination. The stopcocks should be greased with a solution of natural rubber in vaseline that has been freed from absorbed air by boiling in a 
vacuum just before using; all four stopcocks should be rotated at intervals during exhaustion.

The oil manometer was filled with the oil ("standard gas engine") used in the Geryk air pump. This oil is about one-fifteenth the density of mercury, so that pressure readings are greatly enlarged. It was vacuum boiled before using. Since this oil, like so many other similar hydrocarbons, rapidly absorbs air and other gases, it was necessary to make the manometer self-exhausting as shown. The stopcock is left open except when a reading is to be taken. A mercury manometer or McLeod gauge could not be used for measuring the pressure of the helium gas without too great contamination. The vapor pressure of this oil is below that of a nonconducting vacuum except in the warmest summer weather, and then a cold-water jacket is easily applied to both manometer and puinp cylinder.

In filling standard tubes with helium the greatest difficulty is in freeing the electrodes from hydrogen. This is best accomplished by steady pumping while a heavy current is passing through the tube. After but a few minutes pumping nearly all of the impurities except hydrogen will disappear, indicating, perhaps, that the interior walls are clear of gas. After about fifteen minutes further punping the hydrogen pressure drops abruptly. This, I take it, is when the disk portions of the electrodes are depleted of included hydrogen. To completely clear the stems of the electrodes requires further pumping and current for perhaps an hour. No air or helium should be admitted during this process, as it makes the complete elimination of the hydrogen much more tedious and difficult.

After the tube refuses to conduct even a 5000-volt current, helium may be admitted. This usually shows impurities (probably atomized stopcock grease), but these are easily removed by the pump. After two or three fillings, the tube should show only the pure helium spectrum, without a trace of the red hydrogen line, and may be sealed off.

Various other methods of eliminating traces of hydrogen were tried-oxidation and removal as water vapor, absorption by an auxiliary electrode of sodium-potassium alloy, absorption by cold 
palladium and hot calcium and absorption by charcoal in liquid air-but none were found entirely effective.

The purity of helium may be readily judged without a spectroscope by the color of the cathode glow. In pure helium this is of a clear magenta tint, but if there is a mere trace of impurity present, this is lost.

The tubes were operated on a 5000-volt alternating current from a transformer controlled by resistance in its primary. The light emitted was compared with that from a calibrated 4-candle glow lamp by means of a Lummer-Brodhun photometer of the equality type. The uncertainty in each determination is about two per cent, the probable error less than one per cent. In a spectrophotometric comparison, the uncertainty would have been from Io to Ioo per cent on account of the variable line width.

\section{VARIATION OF LIGHT WITH CURRENT.}

The variation of light with current in various forms of tube is shown in the accompanying tables and curves. The light from the whole capillary taken with the tube stationary is given in candles, but is uncorrected for mean horizontal.

\begin{tabular}{l|c|c|c|c|c|c|c|c}
\hline \multicolumn{1}{c|}{ Tube } & \multicolumn{7}{|c}{ Current in Milliamperes } \\
\cline { 1 - 8 } No. & 10 & 15 & 20 & 25 & 30 & 35 & 40 & 45 \\
\hline \multirow{2}{*}{18} & 0.58 & 0.94 & 1.19 & 1.33 & 1.39 & 1.42 & & \\
27 & 0.55 & 0.86 & 1.16 & 1.45 & 1.71 & 1.92 & 2.11 & 2.30 \\
43 & 0.29 & 0.68 & 0.96 & 1.23 & 1.47 & 1.69 & 1.89 & 2.09 \\
39 & 0.60 & 0.92 & 1.23 & 1.54 & 1.83 & 2.06 & 2.30 & 2.53 \\
\hline
\end{tabular}

The dimensions of these tubes are:

No. I8. Capillary I. $2 \mathrm{~mm}$ diameter, $40 \mathrm{~mm}$ long.

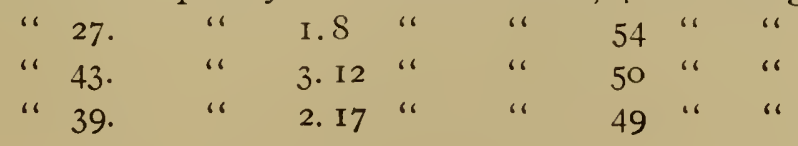


The plotted curves indicate the effect of size of capillary. Tube No. IS with its small bore gives a curve much steeper at the start,

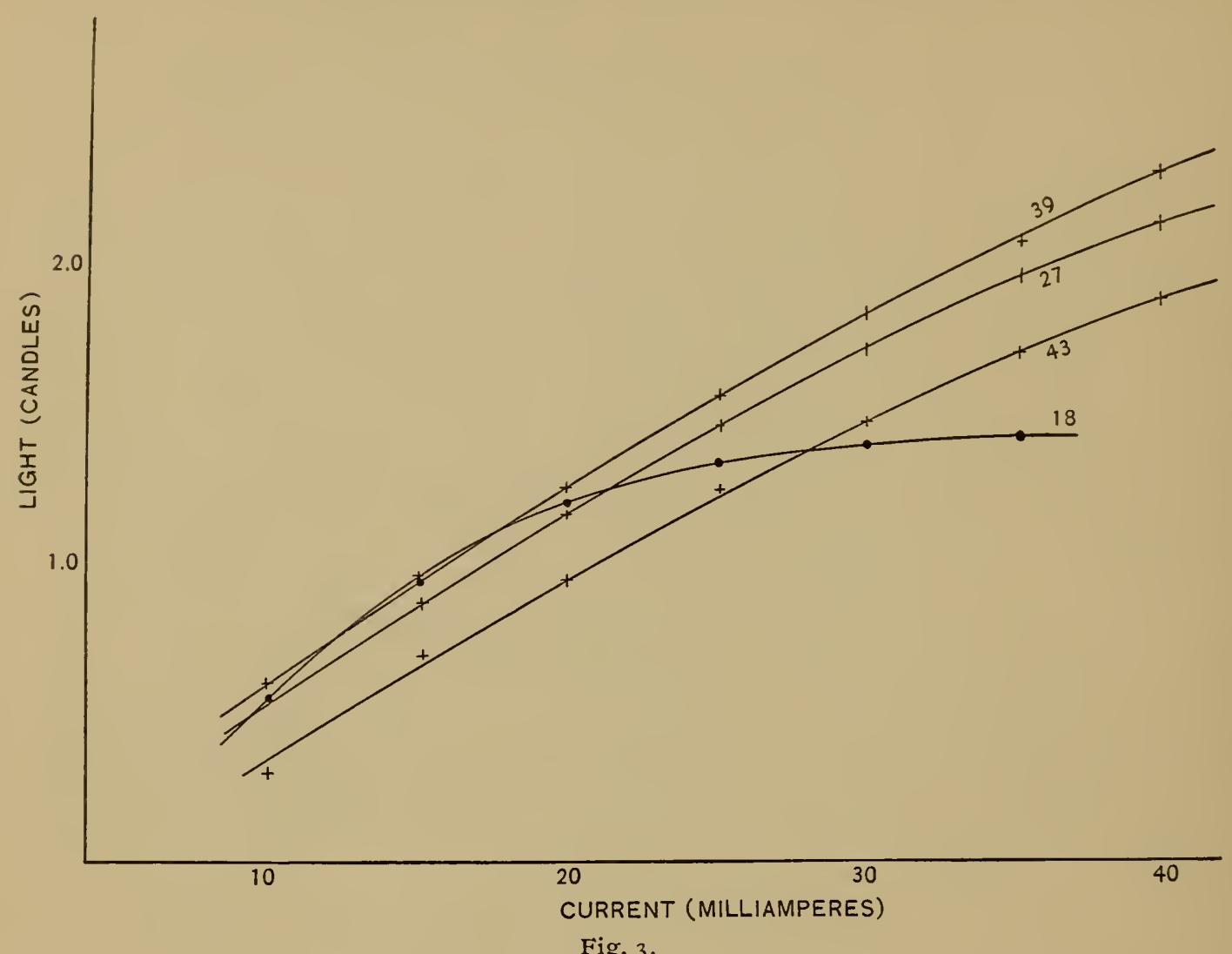

but early approaching a maximum. Tubes of larger bore give curves of less curvature.

More precise corrected values for the variation of light with current obtained later are given below.

\begin{tabular}{c|c}
\hline Current (Milliamperes) & $\begin{array}{c}\text { Correction to Candle Power per cm Length of } \\
\text { Capillary }\end{array}$ \\
\hline 22 & +0.0387 \\
23 & +0.0258 \\
24 & +0.0136 \\
25 & 0.0 \\
26 & -0.0130 \\
27 & -0.0256 \\
28 & -0.0376 \\
\hline
\end{tabular}




\section{VARIATION OF LIGHT WITH POTENTIAL GRADIENT.}

The variation of light with potential gradient was studied with the purpose of expressing light emitted in terms of energy absorbed. Auxiliary potential electrodes of platinum wire were inserted at each end of the capillary portion of the tubes and potential readings taken witl a multicellular voltmeter. It was found that fairly constant potential readings could be obtained. It was found, however, that by playing a flame or blast of cold air upon the capillary a variation of five or ten per cent in the indicated fall of potential could be produced. This variation, however, was not accompanied by a variation in the light emitted so long as the current was held constant.

Some typical data is given in the following tables and curves:

Variation of Potential Gradient with Current

I. Tube No. 38. Capillary 2.17 mm diam., $50 \mathrm{~mm}$ long, Pressure $4.2 \mathrm{~mm}$

II. " " 43 . "3.I2 " $" 50$ "

\begin{tabular}{|c|c|c|c|c|c|c|}
\hline \multicolumn{2}{|c|}{$\begin{array}{c}\text { Current } \\
\text { (milliamperes) }\end{array}$} & $\begin{array}{c}\text { Light } \\
\text { (candle) }\end{array}$ & P. G. (volts) & $\begin{array}{l}\text { Energy } \\
\text { (watts) }\end{array}$ & $\frac{\text { Candle }}{\text { Watt }}$ & $\frac{\text { Watts }}{\text { Candle }}$ \\
\hline \multirow{8}{*}{ (I) } & 10 & 0.60 & 274 & 2.74 & 0.219 & 4.57 \\
\hline & 15 & 0.86 & 256 & 3.84 & 0.227 & 4.40 \\
\hline & 20 & 1.21 & 245 & 4.90 & 0.246 & 4.07 \\
\hline & 25 & 1.50 & 237 & 5.92 & 0.253 & 3.96 \\
\hline & 30 & 1.76 & 233 & 6.99 & 0.258 & 3.88 \\
\hline & 35 & 2.00 & 231 & 8.10 & 0.247 & 4.05 \\
\hline & 40 & 2.24 & 230 & 9.20 & 0.244 & 4.11 \\
\hline & 45 & 2.46 & 229 & 10.30 & 0.239 & 4.19 \\
\hline \multirow{9}{*}{ (II) } & 10 & 0.39 & 233 & 2.33 & 0.169 & 5.92 \\
\hline & 15 & 0.68 & 211 & 3.16 & 0.215 & 4.65 \\
\hline & 20 & 0.96 & 198 & 3.96 & 0.242 & 4.14 \\
\hline & 25 & 1.23 & 190 & 4.75 & 0.259 & 3.88 \\
\hline & 30 & 1.47 & 185 & 5.55 & 0.265 & 3.78 \\
\hline & 35 & 1.69 & 180 & 6.30 & 0.268 & 3.74 \\
\hline & 40 & 1.89 & 176 & 7.04 & 0.268 & 3.74 \\
\hline & 45 & 2.09 & 173 & 7.79 & 0.268 & 3.74 \\
\hline & 150 & 2.28 & 170 & 8.50 & 0.268 & 3.74 \\
\hline
\end{tabular}


The two curves for fall of potential plotted against current are of the typical form for the anode column of a conducting gas. That for the larger capillary is lower and on a larger scale. These curves are of very nearly the same form for all pressures from $2 \mathrm{~mm}$

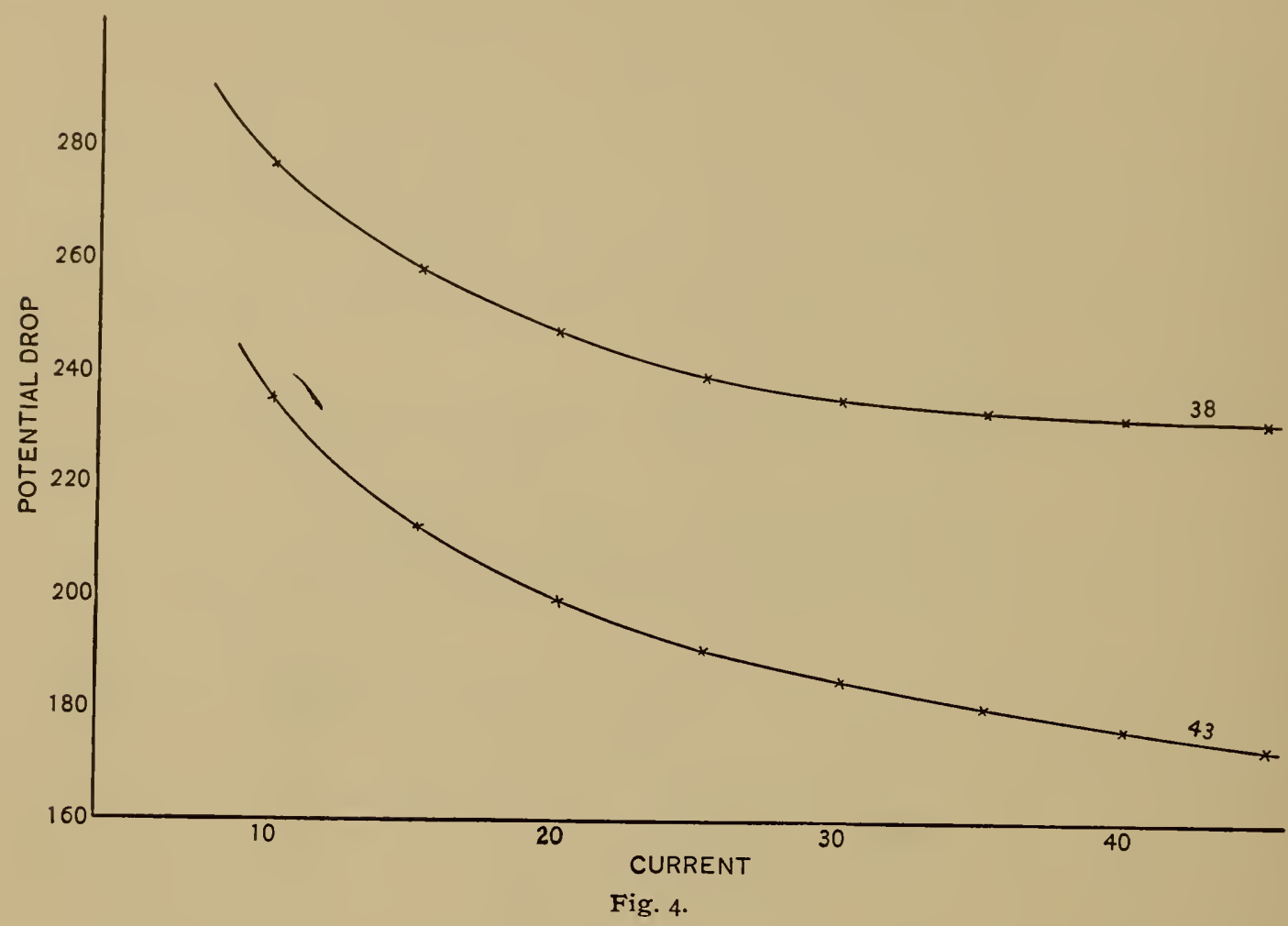

to Io $\mathrm{mm}$, but are a few per cent higher at the higher pressures. If the auxiliary electrodes took up the actual potential of the gas, the above data gives an indication of the luminous efficiency of such a tube. It passes through a maximum at a current density of about 6 milliamperes per square millimeter. The low luminous efficiency of helium is largely due to the three infra-red lines at $728, \operatorname{III} 7$, and $2040 \mu \mu$ which represent at least 90 per cent of the radiation without contributing to the light emitted.

\section{VARIATION OF LIGHT WITH GAS DENSITY.}

The variation of light emitted with density of gas was studied by means of tubes of three different diameters filled with helium at pressures ranging from $2 \mathrm{~mm}$ to $10 \mathrm{~mm}$ and carrying currents of ro to 45 m.a. Gas pressure was measured on a special manometer containing gas-free pump oil of one-fifteenth the density of mercury. 
Each tube was first filled with pure gas at the highest pressure, then the pressure reduced in steps by temporarily connecting with a highly exhausted auxiliary bulb of proper size.

Variation of Light with Gas Density,

Tube No. 43. Capillary $3.12 \mathrm{~mm}$ diam., $50 \mathrm{~mm}$ long

\begin{tabular}{l|l|l|l|l|l}
\hline \multicolumn{2}{c}{ Gas Pressure in mm Hg. } \\
\cline { 1 - 4 } Current & 8.5 & 6.6 & 5.0 & 3.7 & 2.5 \\
\hline 10 & 0.13 & 0.26 & 0.41 & 0.42 & 0.33 \\
15 & 0.34 & 0.52 & 0.71 & 0.75 & 0.65 \\
20 & 0.53 & 0.82 & 1.01 & 1.03 & 0.92 \\
25 & 0.74 & 1.09 & 1.29 & 1.34 & 1.20 \\
30 & 0.92 & 1.31 & 1.54 & 1.58 & 1.53 \\
35 & 1.11 & 1.60 & 1.77 & 1.79 & \\
40 & 1.31 & 1.71 & 1.98 & 1.99 & \\
45 & 1.46 & 2.01 & 2.20 & 2.07 & \\
50 & & 2.12 & 2.40 & 2.17 & \\
\hline
\end{tabular}

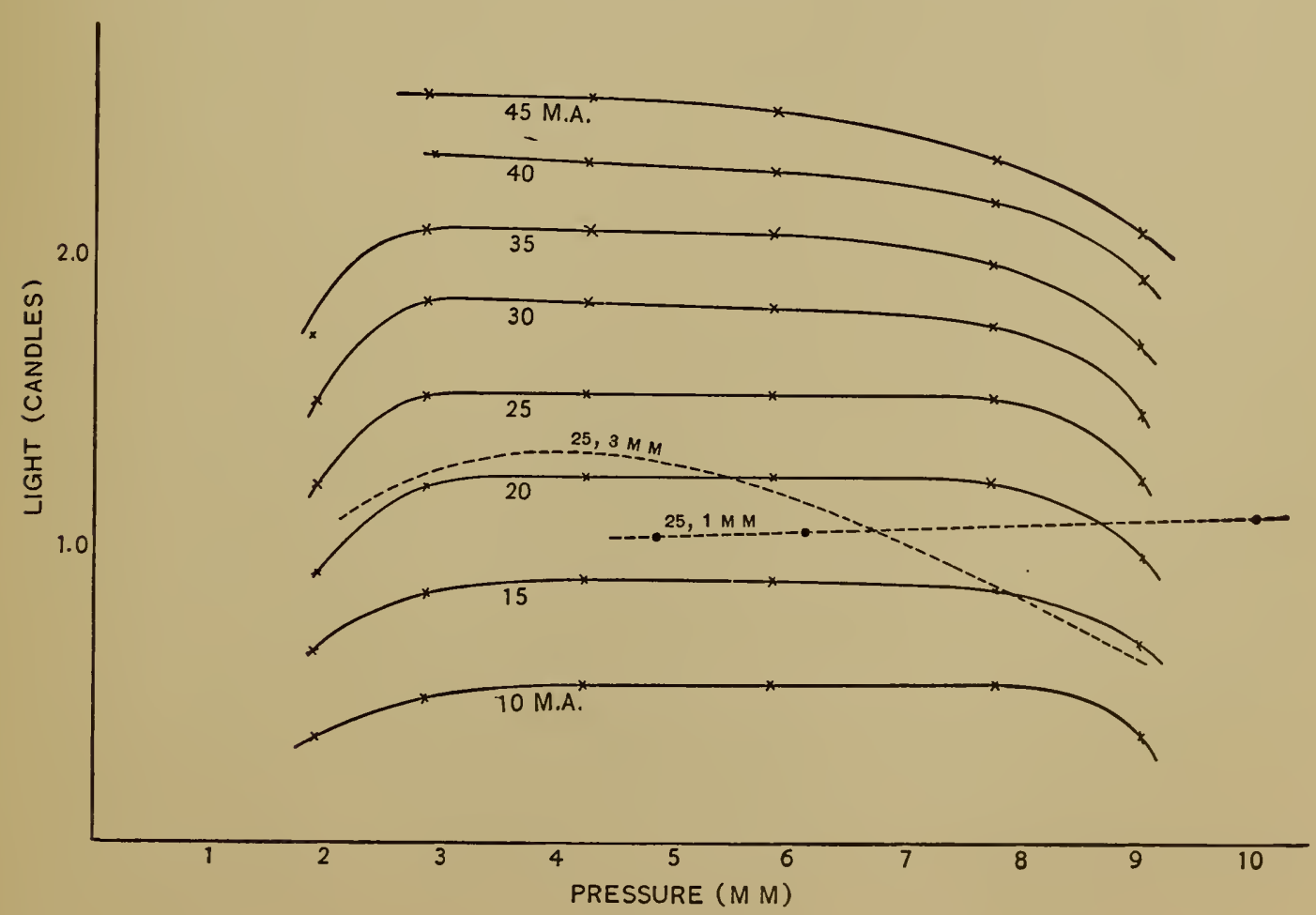

Fig. 5 . 
Tube No. 38. Capillary $2.17 \mathrm{~mm}$ diam., $50 \mathrm{~mm}$ long

\begin{tabular}{c|l|l|l|l|l|l}
\hline \multicolumn{7}{c}{ Gas Pressure } \\
\hline Current & 9.0 & 7.7 & 5.8 & 4.2 & 2.8 & I.9 \\
\hline 10 & 0.38 & 0.55 & 0.55 & 0.55 & 0.48 & 0.08 \\
15 & 0.70 & 0.87 & 0.91 & 0.90 & 0.83 & 0.66 \\
20 & 0.98 & 1.22 & 1.24 & 1.24 & 1.20 & 0.91 \\
25 & 1.25 & 1.51 & 1.54 & 1.54 & 1.54 & 1.24 \\
30 & 1.48 & 1.79 & 1.83 & 1.85 & 1.86 & 1.51 \\
35 & 1.72 & 1.99 & 2.10 & 2.10 & 2.10 & 1.71 \\
40 & 1.96 & 2.20 & 2.31 & 2.35 & 2.07 & \\
45 & 2.11 & 2.35 & 2.47 & 2.56 & 2.58 & \\
\hline
\end{tabular}

Tube No. 45. Capillary I.03 mm diam., $50 \mathrm{~mm}$ long

\begin{tabular}{c|c|c|c}
\hline \multicolumn{3}{|c}{ Gas Pressure } \\
\hline Current & 10.0 & 6.1 & 4.8 \\
\hline 10 & 0.47 & 0.45 & 0.44 \\
15 & 0.25 & 0.67 & 0.66 \\
20 & 0.93 & 0.89 & 0.86 \\
25 & 1.12 & 1.08 & 1.07 \\
30 & 1.25 & 1.21 & 1.19 \\
35 & 1.33 & 1.33 & \\
\hline
\end{tabular}

The complete data on Tube No. $3^{8}$ is reproduced in Fig. 5 with one curve dotted for each of Tubes 43 and 45. The curves for the 2-mm tube parallel the pressure axis over a wide range of pressure and current. For the 3-mm capillary the curves are higher at lower pressures, for the I-mm capillary at high pressures.

\section{USE OF DIRECT AND ALTERNATING CURRENT.}

The form of current was varied from direct to alternating of high and low frequency and voltage without disturbing the apparatus. The direct IOoO-rolt current from two 500-volt generators in series could be controlled at 22.5 m.a. and 23.7 11.a. Afterwards the 
more easily adjustable alternating current was brought to these values. The data taken is as follows:

\begin{tabular}{c|c|c}
\hline \multirow{2}{*}{ Form of Current } & \multicolumn{2}{|c}{ Light Emitted } \\
\cline { 2 - 3 } & Current =22.5 m.a. & 23.7 m.a. \\
\hline Direct current, 1000 volts & 1.21 & 1.30 \\
Alternating ", 5000 volts, 60 cycles & 1.22 & 1.29 \\
" ", 5000 volts, 900 " & 1.21 & 1.29 \\
" ", 2000 volts, 60 " & 1.22 & 1.28 \\
\hline
\end{tabular}

The slight differences observed are less than the uncertainty in the light determinations.

\section{VARIATION OF LIGHT WITH ORIENTATION OF TUBE.}

The light emitted by a tube varies with its orientation on account of irregularities in the capillary. Heavy-walled capillary is worst, deviations of ten per cent from the mean horizontal being not uncommon. Walls I mm thick are sufficiently strong for such tubes, and such thin-walled capillary, if carefully selected, is found to give deviations of but one or two per cent from the mean. Such deviations are of slight consequence when the mean horizontal is obtained.

\section{VARIATION OF LIGHT WITH CURRENT DENSITY.}

The diameter of the capillary affects the light emitted per cm with a given current. Tests of saturation indicated that in such a luminous column of gas practically all the radiation comes from within half a millimeter of the surface, so that light emitted would vary with the area of longitudinal section rather than with volume. Current density varies inversely as the square of the diameter, so that if the light varied directly as the diameter (at constant current density), as above indicated, it should vary approximately inversely as the diameter at constant current. Data is available on four different diameters of capillary at 25 milliamperes of current:

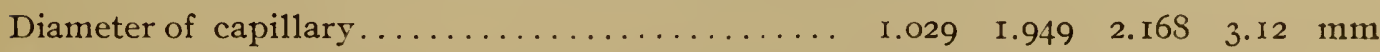
$\begin{array}{lllllll}\text { Mean horizontal candle power per } \mathrm{cm} \text { at } 25 \mathrm{~m} . \mathrm{a} \ldots & 0.365 & 0.325 & 0.3 \mathrm{II} & 0.259\end{array}$ 
These four points lie near a smooth curve that is nearly a straiglit line.

In the light of the above results, the specifications most suitable for constancy and reproducibility in a helium standard of light intensity may be drawn up, namely, a current of 25 milliamperes, a capillary of $2 \mathrm{~mm}$ diameter, and a gas pressure of about $5 \mathrm{~mm}$, which need not be accurately known. Conversely it might be stated that a tube having a capillary of $2 \mathrm{~mm}$ bore, filled with pure helium at 51111 pressure, will einit $\mathrm{N}$ mean horizontal candles per centimeter of length when carrying a current of 25 milliamperes. The constant $\mathrm{N}$ has been shown to be very nearly if not quite independent of other small variations. The uncertainty in the value of $\mathrm{N}$, aside from the uncertainty in its photometric determination, is very small, probably much less than one per cent.

To test reproducibility, a set of six duplicate tubes were made up with capillary $2.168 \mathrm{~mm}$ in mean internal diameter and filled at 5 $\mathrm{mm}$ pressure. These gave the following values in mean horizontal candles per $\mathrm{cm}$ length at 25 milliamperes:

\begin{tabular}{|c|c|c|}
\hline Tube No. & Light per $\mathrm{cm}$. & Deviation from mean. \\
\hline 37 & 0.325 & -0.003 \\
\hline 38 & 0.329 & +0.001 \\
\hline 39 & 0.332 & +0.004 \\
\hline 40 & 0.328 & 0.000 \\
\hline 41 & 0.326 & -0.002 \\
\hline \multirow[t]{3}{*}{42} & 0.326 & -0.002 \\
\hline & Mean & 0.002 \\
\hline & \pm 0.001 & \\
\hline
\end{tabular}

The greatest deviation is only about a per cent, the average deviation less than a per cent, and the probable error in the mean value less than one-third of one per cent.

The correction for bore of capillary is 0.009 from the curve of variation of light with bore, so that this set of tubes gives the value of the constant $\mathrm{N}, 0.337$ candle per centimeter. 
9. VARIATION OF LIGHT WITH TIME.

Incidentally, many tests for a time effect were made. At the end of a long series of observations with varying current or orientation, tubes would be brought back to the initial current or position and their light values checked with previous ones made half an hour before, and these with others made a week or a month previously. In every case values checked up to within the uncertainty of observation. In the few cases where apparent changes were recorded the change was large and due to an obvious change in the tube itself, a crack or the developinent of hydrogen or a cathode deposit due to current overload.

\section{CONCLUSION.}

These results are so promising that the helium tube seems to me to be worthy of consideration as a primary light standard. Its freedom from the troublesome atmospheric corrections to which the Hefner, Carcel, and pentane standards are subject is very much in its favor. The only quantity to be measured while in operation is the current, and this may easily be determined with the required precision.

The uncertainties in the value of the light constant $N$ are of three classes, and these require further investigation before the helium tube may be considered as a competitor of existing standards. These uncertainties are:

I. Those in the separate determinations of the same observer on the same tube. These are not serious, being of the same order as the uncertainties in ordinary photometric work.

2. Uncertainties due to using different tubes. Reproducibility will require further investigation with capillaries of different kinds of glass and of different diameters. If this uncertainty is no greater than is indicated by the test of the six tubes, 37 to 42 , above recorded, it is of little consequence.

3. Uncertainties due to varying the observer on account of color differences. These are the most serious of all, and require careful investigation by many different observers.

Washington, December, I907. 